Images dans le monde ibérique et ibéricoaméricain

9 | 2016

Innovations politiques et culturelles dans les pays andins

\title{
El cine peruano de animación digital o la aparición de un nuevo paradigma audiovisual en América latina
}

\section{Félix Terrones}

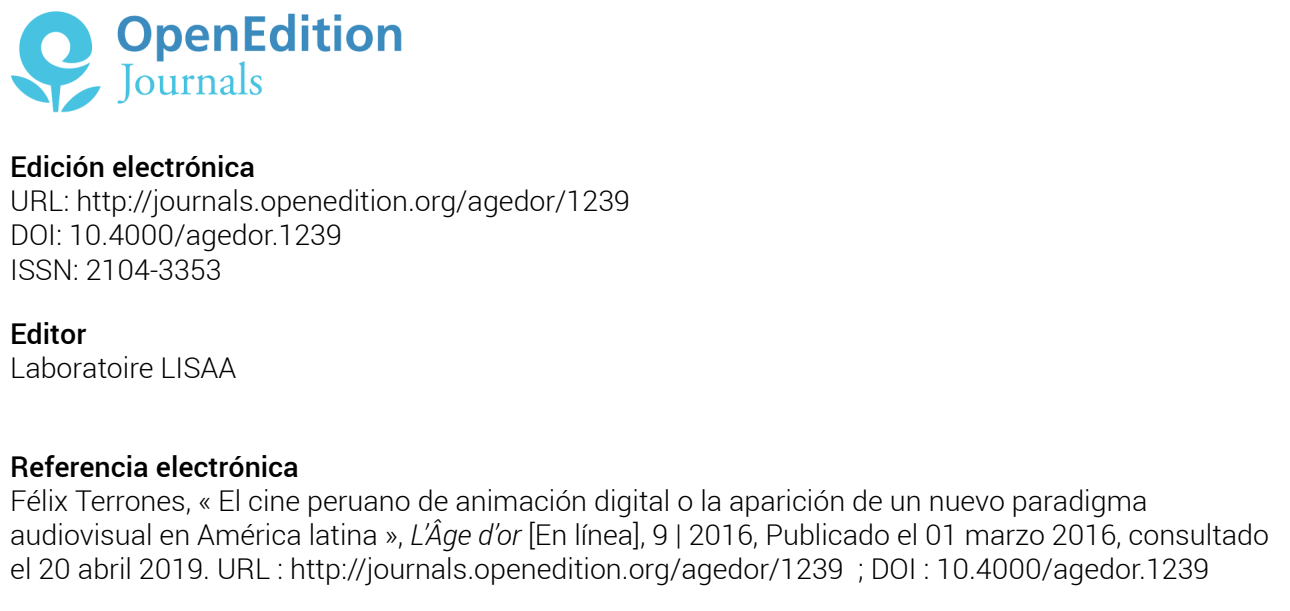

Este documento fue generado automáticamente el 20 abril 2019.

L'Âge d'or. Images dans le monde ibérique et ibéricoaméricain 


\section{El cine peruano de animación digital o la aparición de un nuevo paradigma audiovisual en América latina}

Félix Terrones

1 El éxito de público que supuso Piratas en el Callao (Eduardo Schuldt, 2005), primera película peruana digital en 3D, no sólo significó el primer momento para una nueva forma de entender y abordar la animación en una industria como la peruana, sino que también escondió, en cierta manera, el largo proceso de evolución que cristalizó en ella. Así, contrariamente a lo que se puede pensar, en lugar de ser una eclosión espontánea, Piratas en el Callao representa tanto una culminación como un nuevo punto de partida en la historia del cine nacional. En ese sentido, buscando interrogar y definir la idiosincrasia del cine de animación peruano, trazaremos la evolución de éste a lo largo de las décadas que precedieron el manejo de nuevas tecnologías. Si bien el horizonte cinematográfico nacional ha evolucionado hacia una progresiva, aunque ineluctable, profesionalización técnica y económica, muy acorde con lo que ocurre en otros ámbitos culturales, esto no quiere decir que, desde un inicio, dejaran de manifestarse las características que lo singularizarían frente a la producción cinematográfica de otras latitudes. Por eso, en un primer momento, intentaremos discernir dichas características, las cuales nos permitirán comprender de un mejor modo el momento actual y las problemáticas que le son inherentes. Enseguida, buscaremos abordar la animación digital peruana a partir de lo que tiene de singular en un contexto - el mundial - caracterizado por una estandarización de patrones formales, tecnológicos y temáticos. De la visión panorámica al estudio de casos específicos, nos detendremos, finalmente, en dos películas: Piratas en el Callao y Valentino y el clan del can (David Bisbano, 2008). Subrayando los elementos sociales, culturales y económicos puestos en juego (y en imágenes), abordaremos estas dos películas representativas, cada cual a su manera, de lo que es el cine de animación digital peruano en pleno siglo XXI. 


\section{Los orígenes de la animación peruana o un caso singular}

2 El primer dibujo animado peruano, según el investigador Raúl Rivera Escobar - autor del único estudio dedicado a la materia ${ }^{1}$ fue un cortometraje experimental de cinco minutos, del cual apenas se conoce nada, rodado en diciembre de 1952. Los autores de dicho corto fueron Augusto López y Rafael Seminario quienes se reunieron para, por medio de la empresa El Lápiz Mágico, producir y distribuir sus creaciones. El caso de Rafael Seminario parece, de un modo o de otro, emblematizar lo que en gran medida caracterizaría a los animadores peruanos. Así, lo mismo que muchos de quienes vendrían después ${ }^{2}$, fue un autodidacta ampliamente conocido por sus retratos y dibujos que aparecían en diarios y otros medios conocidos de la época. El vínculo con diversos actores económicos le permitió el contacto con diferentes empresarios que le confiaron la realización de producciones publicitarias para cine y televisión (Inca Kola, Coca-Cola, Camel, etc). Además, Seminario participó en proyectos cuya divulgación fue más allá de las fronteras peruanas al ser promocionados en países como Venezuela, Colombia, Ecuador, Chile y Bolivia.

3 Lo que habría de caracterizar a la animación peruana desde un inicio, fue la convivencia entre el autodidactismo y la profesionalización, la oscilación entre lo local y lo global, y su dependencia de capitales privados y públicos para su desarrollo. Así, por ejemplo, desde los cincuenta hasta los noventa, una gran parte de las producciones animadas peruanas se encuentran vinculadas con fines comerciales. La razón de este vínculo es antes que nada financiera, puesto que las grandes empresas solicitan el concurso de los animadores para que, por medio de salarios considerables, realicen producciones que serán proyectadas a un público consumidor en potencia. Esto explica el incremento sistemático de estudios de animación en Perú, así como su progresiva especialización en anuncios (spots). Sin embargo, esto también se traduce en cierta falta de horizonte: los estudios de producción no duran mucho, no existen planes a mediano o a largo plazo, los animadores deben dedicar la mayor parte de su tiempo y energías a la publicidad, en lugar de embarcarse en proyectos de mayor envergadura formal y estética.

Existen dos momentos que merecen un párrafo aparte, si se quiere entender el desarrollo de la animación en el Perú. El primero es la temprana aparición de una empresa nacional orientada a ser un referente en cuanto a producción cinematográfica se trata: Amauta Films. Fundada en 1937, Amauta Films fue una empresa que buscó producir obras que mostraran la personalidad del país; según Luis Trelles Plazaola, mediante "un cine de carácter popular"3. Fueron los mismos integrantes de la productora quienes enumeraron las razones que los llevaron a formar una empresa de animación. Entre otras, enunciaron las siguientes: "para revelar nuestro paisaje virgen a la contemplación del mundo", "para ensayar la conciliación del gusto y la taquilla", "para conquistar el mercado continental a fuerza de capital y técnica" y "para demostrar no sólo que podemos hacer sino que podemos superar". Es interesante subrayar la forma en que conjugan elementos culturales con factores comerciales. De esta manera procuraban, al menos en términos retóricos, subrayar la idiosincrasia cultural y encontrar un lugar en un mercado - el latinoamericano - dominado antes que nada por los mexicanos y los argentinos. Ahora bien, "Amauta films" se terminó disolviendo muy poco después, paradójicamente por culpa de todo aquello que buscó combatir. Según el crítico de cine Ricardo Bedoya, citado 
por Rivera Escobar, su ocaso fue consecuencia de "la insuficiente calidad, tanto técnica o artística, (...) y el reducido mercado que abarcaban (por su temática populista, estaban destinadas, por lo común, a un público local)"'5. Cuando se trata de animación nacional, las primeras expresiones de ésta, aparecieron tiempo después del fracaso de Amauta Films, en un contexto socioeconómico difícil, aunque no por ello menos estimulante. Teniendo como trasfondo los planteamientos rectores de Amauta Films, los animadores peruanos declinarían a su manera la necesidad de cifrar la idiosincrasia social en un mercado no necesariamente, aunque casi siempre, limitado al consumo nacional.

5 Un segundo momento relevante para la animación en el Perú, ya directamente relacionado con su desarrollo, es el del gobierno del general Juan Velasco Alvarado (1968-1975) quien promovió la ley 19327, promulgada en 1971. Raúl Rivera Escobar no se impide criticar las medidas de Velasco Alvarado con respecto de los medios de comunicación (a los cuales nacionalizó para después arbitrar, entre otras cosas, los contenidos de las campañas publicitarias), lo cual no puede negar el hecho de que a lo largo de sus veintiún años de existencia se realizaron, por ejemplo, veintitrés cortos animados. Esta eclosión cuantitativa se debe a que el Estado procuró crear un medio ambiente adecuado, en términos jurídicos, administrativos y presupuestarios, para permitir el desarrollo de la cinematografía. Entre otras disposiciones, por ejemplo, se estableció la exhibición obligatoria de películas en el circuito nacional de salas, así como también se exoneró de impuestos y arbitrios, entre el $100 \%$ (largometrajes) y el $25 \%$ (cortometrajes). Estas medidas modificaron radicalmente la realización cinematográfica animada pues permitieron producciones alternativas a las publicitarias, de mayor presupuesto y calidad, así como una exploración temática y formal pocas veces vistas antes.

\section{La introducción de la animación digital y la consolidación de un fenómeno}

6 El auge de la animación es de este periodo, el cual terminó en diciembre de 1992 mediante la derogatoria de la ley 19327. Por medio de dicha derogatoria, se suprimía la destinación del impuesto municipal a los productores, así como la exhibición obligatoria de las películas (según la estudiosa María del Carmen Fernández Trujillo esto último se justificó aduciendo "la violación del derecho constitucional de la libertad de comercio"). Los críticos e investigadores de cine peruano están de acuerdo de forma unánime cuando se trata de evaluar los efectos negativos de la derogación en el desarrollo del emergente cine nacional. Pese a que se emitió una nueva ley, la 26370, orientada a fomentar la producción nacional, impulsando su perfeccionamiento ${ }^{7}$, según lo expresado en el mismo texto de ésta, no solo se restringió el apoyo material a la producción nacional, sino que se le abandonó en un combate desigual frente a mercados de mayor alcance como el americano.

7 Si bien con dicha derogatoria se quitaba un apoyo importante a la producción cinematográfica, no se puede negar que durante el primer gobierno de Alberto Fujimori (1990-1995) se da un desarrollo exponencial de la animación digital en el Perú8. Así, por ejemplo, podemos contar un total de veintidós productoras audiovisuales creadas a lo largo de esta década9. Dichas casas de producción, si bien en constante dependencia de los encargos de animación digital, solicitados por empresas nacionales e internacionales, 
representan una transformación del universo de la animación a nivel formal y estético, pero también comercial. Es durante este periodo, por otro lado, que aparecen o se consolidan una gran parte de las instituciones que forman académica y profesionalmente a quienes después se integrarán al sector de la animación: el Toulouse Lautrec abre la carrera de Diseño publicitario y comunicación audiovisual; el ISIL y CIBERTEC, la carrera de Diseño gráfico; entre otros. La emergente oferta educativa se ve traducida en una progresiva, aunque ineluctable, autonomización del campo a escala nacional. Las nuevas promociones de diseñadores cuentan no sólo con una experiencia académica sino también con la posibilidad de incorporarse de inmediato al circuito de la animación. En efecto, muchos de quienes trabajan como docentes en las diversas instituciones académicas son propietarios de estudios de animación o tienen un lugar influyente en el mercado (Pepe San Martín, Carlos Morán, Benicio Vicente, entre otros). Ocurre incluso que los mismos egresados funden una productora, tal y como se dio con Magma Creations (formada por ex estudiantes de Toulouse Lautrec).

8 Conforme la propuesta educativa se fue asentando y el trabajo de las productoras de animación afirmando, las ofertas laborales no solo se limitaron al espacio nacional, sino que también se extendieron al mercado internacional. Un ejemplo de este punto, es la sonada convocatoria que Joaquín Escandón y Javier Álvarez recibieron para intervenir en el rodaje de The Chronicles of Narnia: The Lion, the Witch and the Wardrobe (Andrew Adamson, 2005). Se trataba de colaborar en una película norteamericana de alto presupuesto y exigencia técnica cuya productora se valía del procedimiento de la tercerización para abaratar costos y acelerar el trabajo. Para esto, ambos profesionales viajaron hasta Guatemala donde funcionaba el Estudio C, empresa que debía ocuparse de crear digitalmente una serie de icebergs para una de las secuencias de la película. La experiencia les sirvió para enriquecerse con un trabajo más profesionalizado y también para comenzar a introducirse en el mercado internacional. Si extendemos un poco más el sector profesional en el que se mueven los nuevos animadores nacionales podemos decir que, lo mismo que en muchos otros países latinoamericanos, en Perú muchas empresas terminan solicitando sus servicios profesionales para realizar videojuegos. Dichos videojuegos, los cuales son difundidos tanto a escala nacional o internacional, se dirigen a un público consumidor de los productos patrocinadores.

9 Subrayemos que la producción digital de animación se encuentra orientada antes que nada a la publicidad y la realización de cortometrajes y largometrajes. En ese sentido, pareciera prolongar las primeras décadas de animación peruana, durante las cuales la emergente producción debía buscar su financiamiento entre las empresas deseosas de comercializar sus productos y servicios. En el caso de proyectos de mayor envergadura, como los largometrajes, los cuales ya sin la ley 19327 deben buscar un financiamiento particular, cuando no presentarse a diversos premios que permitan solventar y difundir sus obras (tal es el caso, por ejemplo, de la artista Susana Perrottet quien en el 2012 ganó el premio VIP MFA de New York). En el tercer acápite nos detendremos en el caso de los largometrajes, en cuanto a los cortometrajes es necesario señalar que, pese a la poca ayuda gubernamental, pues CONACINE no cuenta con el presupuesto adecuado, se producen cortos de autor muy singulares tanto en su concepción como en sus alcances ideológicos. En ese sentido me gustaría recordar el trabajo de Jossie Malis y Christian Alarcón Ismodes. Si bien diferentes en sus propósitos, puesto que cada uno tiene una estética singular, la del primero evocativa mientras que la del segundo más directa y combativa, ambos artistas digitales han sabido crear un lenguaje personal en el que se 
mezclan elementos prehispánicos, sobre todo en el estilo, con inquietudes contemporáneas que van de la ecología a la globalización, pasando por el mestizaje.

\title{
La productora Alpamayo y dos casos emblemáticos: Piratas en el Callao y Valentino y el clan del can
}

Hablar de largometrajes de animación digital en el Perú no se puede hacer sin mencionar la derogación de la ley 19327 durante el gobierno fujimorista. Dicha derogatoria, planteada como un paso decisivo para llevar una reforma integral del mercado cinematográfico, terminó convirtiéndose en un retroceso para la producción nacional. De ahí que, sin el apoyo estatal, no solo el número de producciones de animación bajara con respecto del periodo durante el cual dicha ley estuvo vigente, sino que también se tuviera que esperar mucho tiempo antes de que por fin aparecieran largometrajes de animación digital. Pese a las ofertas educativas, la multiplicación del número de productoras, los esfuerzos en el ámbito de la animación digital se restringieron casi exclusivamente a la publicidad. Así, el mercado de animación digital peruano recién emergió doce años después de ser derogada la ley, cuando apareció Alpamayo Entertainment (empadronada en el 2004 en el Registro Único de Contribuyentes) para revolucionar el sector, tal y como lo señala Juan Diego Dianderas, docente en el área de animación del Instituto ToulouseLautrec:

\begin{abstract}
A nivel regional ¿cómo estamos situados?
Nosotros dimos un paso interesante cuando Alpamayo sacó la película de piratas. Con errores o aciertos, puso la piedra de toque y dio inicio a una producción que se ha vuelto interesante. De su no existencia pasó a tener una película animada cada dos años, por lo menos. Se está produciendo no solo el fenómeno de producción, sino que también se ha abierto un interés académico para estudiar animación dentro del país, que antes no existía. Experiencias anteriores, de los 90 hacia atrás, todas han sido usualmente gente que aprendió por su propia cuenta. ${ }^{10}$
\end{abstract}

Formada por iniciativa del político Hernán Garrido Lecca, Alpamayo Entertainment ${ }^{11}$ marca no solo el inicio de la producción de cine de animación digital en América latina sino que, a decir de Raúl Rivera Escobar, sienta las bases "por primera vez en el país, de una verdadera industria de la animación de entretenimiento, de alcance internacional" ${ }^{12}$. En ese sentido, Alpamayo Entertainment se interesó tanto en aspectos formales como en elementos relacionados con la divulgación y el marketing. Así, utilizó 3D para animar sus dibujos, como también buscó una presencia en salas a nivel nacional, y promovió la venta de merchandising relacionado con la cinta, lo cual abrió las puertas a una, hasta entonces desconocida, promoción de una producción nacional. Si bien desde el primer largometraje fueron evidentes las carencias en sus producciones, sobre todo en el acabado de los personajes y la coherencia de los guiones, también es cierto que desde un inicio mostraron un particular olfato por divulgar su trabajo tal y como lo demuestran los premios recibidos; entre otros, el Effie de Oro (2006) por Piratas en el Callao y el Effie de Plata (2007) por Dragones, destino de fuego (Eduardo Schuldt, 2006).

Las dos películas, a nuestro parecer emblemáticas de lo que fue Alpamayo Entertainment, fueron Piratas en el Callao y Valentino y el clan del can (David Bisbano, 2008); es decir, la primera y la última película de la productora. La primera, dirigida por Eduardo Schuldt, es una adaptación de la novela homónima de Hernán Garrido Lecca (productor de la película). Se trata de la historia de Alberto Cabello Quintana quien, durante un paseo por 
la Fortaleza del Real Felipe, viaja en el tiempo hasta el siglo XVII, cuando el pirata Jacques l'Hermite se dispone a atacar el puerto del Callao. De esta manera, se presenta a los niños un relato de orden histórico que da lugar a las aventuras de capa y espada en las que la solidaridad con respecto de los indígenas, el valor de la amistad y la lucha maniquea del bien contra el mal son una constante. Pese al componente histórico, la intriga es abordada desde una perspectiva que resalta elementos dramáticos susceptibles de ser comprendidos por los espectadores de otras latitudes, no necesariamente familiarizados con el ataque holandés. No obstante, es conveniente precisar que producir una película abordable para todo tipo de auditorio no impidió que se utilizase un lenguaje que abunda en localismos como "ómnibus", "florear" y "sonsonazo", entre otros, sin contar con la dicción limeña bastante reconocible, lo cual muestra bien el público al cual está dirigida originalmente la película. Ahora bien, pese a lo prometedor que significaba el ser la primera película de animación digital en 3D, los planos poco dinámicos, la falta de brillo y vida en las imágenes, son elementos que no solo muestran la poca experiencia del director, se trataba de su primera película, sino también las deficiencias técnicas y presupuestarias (el coste estimado es de 500.000 dólares, mientras que The Incredibles [Brad Bird, 2004] de Pixar, estrenada un año antes, costó 92.000.00013).

13 Valentino y el clan del can muestra a diferentes niveles la evolución de Alpamayo. Si bien todavía adolece de deficiencias en cuanto a la imagen - pese a que los personajes sean menos rígidos, muestran mayor riqueza en sus emociones -, otros aspectos resultan reveladores como, por ejemplo, la elección de una historia menos "local" a favor de una más global, que no esconde el paralelo con el clásico de Disney Lady and the Tramp (Clyde Geronimi, Wilfred Jackson, Hamilton Luske, 1955). En un afán por trascender las fronteras nacionales, Alpamayo Entertainment se asoció con TV Azteca de México para coproducir la película y obtener un auditorio de envergadura latinoamericana. Eso explica la presencia de la conocida actriz mexicana Mariana Ochoa (voz de Bianca) quien comparte el protagonismo con Christian Meier (voz de Valentino), el actor peruano de mayor proyección en aquel entonces. Asimismo, las marcas locales se han reducido notablemente no solo en lo que corresponde a la dicción sino sobre todo en los decorados, los cuales imitan una ciudad cualquiera del siglo XIX.

Cabe añadir que existen alusiones a producciones cinematográficas del mismo género o de otros, como el cine mudo, King Kong (Merian C. Cooper, Ernest B. Schoedsack, 1933), Lady and the Tramp, Game of Death (Robert Clouse, 1978) o, incluso, The Matrix (Larry Wachowski, Andy Wachowski, 1999). Se trata de guiños a múltiples niveles dirigidos más bien a un público adulto que, al mismo tiempo, muestran el paisaje audiovisual al cual buscan adscribirse estas películas, el hollywoodense. Producidas en los márgenes del mercado mundial, la periferia de la animación digital, Piratas en el Callao y Valentino y el clan del can son ejemplos de la emergencia de un nuevo paradigma cinematográfico en cuanto se refiere a producción y técnicas de animación. Al mismo tiempo, aunque a su manera, renuevan las características de cierto cine latinoamericano cuando se trata de su búsqueda de un lenguaje formal y temático propio que no excluye la interacción con el cine producido en otras áreas culturales, antes que nada la norteamericana.

\section{Conclusiones}

Entre la imitación formal y temática del cine americano, por un lado, y la singularidad de relatos que evocan e interrogan la realidad y/o la historia nacional, por el otro: el cine de 
animación digital peruano plantea una cualidad liminar que interpela a múltiples niveles. En ese sentido, es un fenómeno social y cultural reciente que debe ser abordado en toda su originalidad, pero también con conciencia de la evolución del género en Perú, un país de índole múltiple e híbrida. Así, por su manera de evolucionar en un contexto no siempre acogedor o estimulante, podemos decir que su desarrollo ha estado pautado por el apoyo institucional (privado o público) y otras formas de financiamiento y consagración (premios internacionales, por ejemplo). De esta manera se pueden entender, primero, la convivencia entre cierto empirismo y la progresiva, aunque nunca terminada, profesionalización del sector. Al mismo tiempo, el marco legal y sus sucesivas transformaciones han determinado la evolución del circuito de animación, desde una incipiente aunque pujante industria, iniciada hacia los años cincuenta, hasta el fenómeno Alpamayo que plantea una manera novedosa de producir y consumir películas animadas, no sólo en Perú sino también en el resto de América latina. Imágenes, sueños, en ocasiones pesadillas, los cortos o largometrajes de animación digital peruanos representan diversas maneras de interactuar con la realidad nacional, que van desde el compromiso político hasta el producto de consumo masivo, pasando por la búsqueda estética. Si algo reúne las producciones de animación actuales es el asentamiento efectuado por Alpamayo de unas bases para abordar la producción de manera más acorde con el de una industria. No obstante, todavía no vemos herederos o sucesores que vayan en este rumbo. Ochenta años después del gesto germinal de Amauta Films, el cual determinó y anunció la cinematografía posterior, la animación digital peruana parece seguir buscando un espacio a escala continental y mundial para sus realizaciones; lo que ocurra en los próximos años dependerá tanto del talento de los cineastas como del olfato de los productores. Por lo pronto, estrenos inminentes como el de la película Ainbo (José Zelada, 2017) parecen afirmar y enriquecer los senderos del cine de animación.

\section{NOTAS}

1. RIVERA ESCOBAR Raúl, El cine de animación en el Perú, Lima, Universidad Alas Peruanas, 2012, 315 p. Este libro es la versión editada de la tesis de licenciatura presentada en el 2010 por el mismo investigador en la UNMSM.

2. Podemos citar como ejemplo de artistas que se formaron a sí mismos a Félix Nakamura, Benicio Vicente, Hugo Guevara y Pedro Vivas, entre muchos otros menos importantes en la historia de la animación peruana.

3. TRELLES PLAZAOLA Luis, South-American Cinema: Dictionary of Film Makers, San Juan (Puerto Rico), La Editorial, 1990, p. 212.

4. BEDOYA WILSON Ricardo, "Recordando a Amauta films setenta años después", Páginas del diario de Satán. Documento electrónico [http://paginasdeldiariodesatan.blogspot.fr/2007/08/ recordando-amauta-films-setenta-aos.html] (última conexión 19/11/2017).

5. RIVERA ESCOBAR, op. cit., p. 40. Al respecto, cabe añadir lo formulado por el investigado peruano Javier Protzel, quien aborda el trabajo de Amauta Films desde una óptica comercial y temática: "En este marco debe mencionarse la rica experiencia de la productora Amauta Films, que apenas en cinco años (1936-1940) estrenó trece largometrajes dentro de un movimiento más 
amplio, que de 1936 a 1948 terminó veintiocho películas de ficción. ¿Pueden llamárseles a estas obras verdaderamente un "cine nacional"? Habría que responder afirmativamente si por ello entendemos, por un lado, inversiones y esfuerzos profesionales y artísticos de gente radicada $u$ oriunda en este país contra viento y marea de mercados copados por Hollywood, y por otro, la toma de referentes narrativos y tipos humanos locales para traducirlos al lenguaje del cine. Pero a la inversa, habría que ponerlo en duda si juzgamos la corta duración del proyecto, la cantidad limitada de espectadores que convocó, y a las películas mismas por su falta de representatividad antropológica y temática, así como sus limitaciones expresivas" in PROTZEL Javier, Imaginarios sociales e imaginarios cinematográficos, Lima: Universidad de Lima, 2009, p. 228-229.

6. FERNÁNDEZ TRUJILLO María del Carmen, Cine, sociedad y cultura en el Perú de los noventa: análisis temático de tres cortometrajes realizados por jóvenes directores, Lima, Universidad Nacional Mayor de San Marcos, Facultad de Letras y Ciencias Humanas, EAP de Comunicación Social, 2003, capítulo II, p. 17. Documento electrónico. [http://sisbib.unmsm.edu.pe/bibvirtual/tesis/human/ fernández_t_m/cap_2.htm\#33r] (última conexión: 19/11/2017).

7. El texto de la ley puede ser leído en el siguiente enlace. Documento electrónico [http:// www.programaibermedia.com/wp-content/uploads/2013/06/Per\%C3\%BA-Ley-de-

Cinematografia-Peruana-Ley-26370.pdf] (última conexión: 27/11/2017).

8. Si bien las primeras manifestaciones de animación digital en nuestro país se dieron hacia mediados de los ochenta, gracias a la productora Chroma, no fue sino en la década de los noventa que tuvo lugar una verdadera explosión a todo nivel. La productora Chroma fue fundada por Hugo Guevara y Óscar Álvarez quienes entre otras técnicas introdujeron la del morphing, famosa por el video de Michael Jackson, Black or White (1991), la de animación en 3D entre otros.

9. Remito a la lista elaborada por Raúl Rivera Escobar en el libro mencionado.

10. “Perú Anima 2014, el Festival de la Animación de Toulouse Lautrec". Documento electrónico [ http://www.codigo.pe/publicidad/peru-anima-2014-el-festival-de-la-animacion-de-toulouselautrec/] (última conexión: 19/11/2017).

11. Las producciones de Alpamayo Entertainment son tres: Piratas en el Callao, Dragones, destino de fuego y Valentino y el clan del can. Pese al unos comienzos prometedores, la productora terminó disolviéndose poco después del tercer largometraje.

12. RIVERA ESCOBAR Raúl, op. cit., p. 143.

13. Información proporcionada por IMDB (Internet Movie Data Base). Documento electrónico [ http://www.imdb.com/title/tt0317705] (última conexión: 19/11/2017).

\section{RESÚMENES}

A partir del estudio de casos representativos, articulados de manera cronológica, interrogamos la evolución de la animación peruana desde su emergencia hasta el momento actual. Así, subrayaremos su progresiva profesionalización en un mercado cada vez más internacional, sin olvidar su interacción con el, favorable o no, ámbito institucional estatal. En este contexto, son delineadas las estrategias con las que la animación peruana acentúa progresivamente su voluntad de insertarse en la industria a escala mundial. Entre lo local y lo global, la animación peruana manifiesta la necesidad de dar forma a temáticas nacionales, pero sin descuidar el potencial público extranjero. 
À partir de l'étude de cas représentatifs, agencés de façon chronologique, nous interrogerons l'évolution du cinéma d'animation péruvien, depuis son apparition jusqu'à nos jours. Ainsi, nous soulignerons sa professionnalisation progressive dans un marché de plus en plus international, sans toutefois oublier son interaction, positive ou non, avec les institutions étatiques. Dans ce contexte, nous mettrons en évidence les stratégies mises en œuvre par le cinéma d'animation péruvien qui révèlent sa volonté de s'insérer dans l'industrie cinématographique internationale. Entre le local et le global, l'animation péruvienne manifeste son besoin de donner forme à des thématiques d'ordre national, sans négliger pour autant son potentiel public étranger.

ÍNDICE

Mots-clés: animation numérique, industrie cinématographique, loi 19327, marché international, identité, Alpamayo Producciones

Palabras claves: animación digital, industria cinematográfica, ley 19327, mercado internacional, identidad, Alpamayo Producciones

\section{AUTOR}

\section{FÉLIX TERRONES}

École normale supérieure (Ulm) 